\title{
Inhibition of TLR4/TRIF/IRF3 Signaling Pathway by Curcumin in Breast Cancer Cells
}

\author{
Gamze Guney Eskiler ${ }^{1 *}$, Asuman Deveci Ozkan ${ }^{1}$, Suleyman Kaleli ${ }^{1}$ and Cemil Bilir ${ }^{2}$ \\ ${ }^{1}$ Department of Medical Biology, Faculty of Medicine, Sakarya University, Sakarya, Turkey \\ ${ }^{2}$ Department of Medical Oncology, Faculty of Medicine, Sakarya University, Sakarya, Turkey \\ Received, April 5, 2019; Revised, May 9, 2019; Accepted, June 11, 2019; Published, July 2, 2019.
}

\begin{abstract}
Purpose: Toll-like receptor 4 (TLR4) is over-expressed in breast tumors and thus contributing to the tumor progression and metastasis. Natural products have drawn attention in cancer immunotherapy due to their various biological activities. Curcumin is well investigated in different types of cancer. However, the mechanisms underlying its anti-inflammatory actions have not been extensively elucidated. For this purpose, we explored the inhibitory effects of curcumin on lipopolysaccharide (LPS)-induced TLR4 dependent TRIF signaling pathway in two subtypes of breast cancer cell lines (MCF-7 and MDA-MB-231) in this study. Methods: In this context, the cytotoxicity of curcumin and LPS alone and the combination of curcumin with LPS on these cells was evaluated by WST-1 assay. The expression level of TLR4 and the release of type I interferon (IFN) levels were determined after treatment with curcumin and/or LPS by RT-PCR and ELISA analysis, respectively. Furthermore, the subcellular localization of TLR4 and interferon regulatory factor 3 (IRF3) were detected by immunofluorescence analysis. Results: Curcumin treatment suppressed breast cancer cells viabilities and the activation of TLR4-mediated TRIF signaling pathway by the downregulation of TLR4 and IRF3 expression levels and the inhibition of type I IFN (IFN- $\alpha / \beta)$ levels induced by LPS. However, curcumin was more efficient in MDAMB-231 cells than MCF-7 cells owing to its greater inhibitory efficacy in the LPS- enhanced TLR4 signaling pathway. Furthermore, IFN- $\alpha / \beta$ levels induced by TLR4 and IRF3 were decreased in these cells following curcumin treatment. Conclusions: Consequently, these results demonstrated that the activation of LPS stimulated TLR4/TRIF/IRF3 signaling pathway was mediated by curcumin in breast cancer cells, in vitro. However, more studies are necessary to examine the curcumin's anti-inflammatory activities on TLR4/MyD88/NF-kB as well as other signaling pathways downstream of TLRs in breast cancer.
\end{abstract}

\section{INTRODUCTION}

Toll-like receptors (TLRs) play a crucial role in immune response by recognizing pathogenassociated molecular patterns (PAMPs) associated with cancer and/or other diseases through different intracellular signaling pathway (1-3). TLRs display different effects in tumor progression and treatment according to the activation of TLRs or TLR associated signaling cascades (4). In tumor progression, TLRs are overexpressed in different types of cancers including lung, prostate and breast and promote survival of cancer cells (5-9). Toll-like receptors 4 (TLR4) is one of the most important member of the TLR family and is stimulated by lipopolysaccharide (LPS) (10). TLR4, which is highly expressed in breast cancer cells, exhibits a tumor-promoting role, and promotes resistance to apoptosis and metastasis. For example, TLR4 and myeloid differentiation primary response gene 88 (MyD88) expression levels in MCF-7 breast cancer cells are increased by LPS stimulation while the knockdown of TLR4 signaling inhibits the survival of breast cancer cells $(11,12)$.

The activation of TLR4 signaling by LPS promotes two different pathways including MyD88 dependent and MyD88 independent TIR domain containing adapter inducing IFN- $\beta$ (TRIF) pathways. MyD88 dependent pathway is regulated by TIRAP (TIR domain-containing adaptor protein), Interleukin-1 receptor-associated kinases 2 and 4 (IRAK2 and IRAK4), TNF receptor associated factor 6 (TRAF6) and release of NF- $\mathrm{KB}$ and induces release of different proinflammatory cytokines including IL-1 $\beta$, TNF- $\alpha$ and IL-6. However, the activation of MyD88 independent TRIF pathway is based on the internalization of TLR4/TRIF

Corresponding Author: Gamze Güney Eskiler: E-Mail: gamzeguney@sakarya.edu.tr, Department of Medical Biology, Medical Faculty, Sakarya University, Korucuk Campus, Sakarya, Turkey. 
endosomal complex in contrast to MyD88dependent pathway. This pathway is mediated by TRIF-related adaptor molecule (TRAM), phosphorylation of interferon regulatory factor 3 (IRF3) and initiation of interferon $\beta$ (IFN- $\beta$ ) transcription (13-16).

Curcumin is isolated from Curcuma longa L. rhizomes and many studies have shown that curcumin exerts the anti-inflammatory, anti-viral, anti-carcinogenic, anti-proliferative and anti-oxidant properties. In the literature, curcumin can potentially inhibit the proliferation of cancer cells and enhance chemotherapeutic drugs sensitivity by inducing apoptosis (17-20). Curcumin can suppress the inflammation via the down-regulation of the extracellular TLRs activation and the inflammatory genes and/or transcription factors $(21,22)$. There has been a number of studies indicating the suppressive effect of different natural products (shinbaro3, curcumin, tanshinones, phloretin, xanthohumol, celastrol, garlic compounds etc.) on the different TLRs signaling (14, 23-26). Additionally, several promising natural compounds (shinbaro3, curcumin, tanshinones) exert anti- inflammatory activities by suppressing TLR4/MyD88/NF-kB pathway. However, there has been no study that investigated the potential effects of curcumin on the activation of TLR4/TRIF/IRF3 signaling pathway in breast cancer, to our knowledge. For this purpose, we explored the anti-inflammatory effects of curcumin on LPS stimulated TLR4/TRIF/IRF3 signaling pathway in two different types of breast cancer cell lines.

\section{METHODS}

\section{Culture conditions for cells proliferation}

MCF-7 and MDA-MB-231 cells were used in this study. These cells were incubated in Dulbecco's modified Eagle's medium (DMEM, Thermo Fisher Scientific, USA) with $10 \%$ heat-inactivated fetal bovine serum (FBS) (Gibco, Thermo Fisher Scientific, USA) and $1 \%$ penicillin/streptomycin (Gibco, Thermo Fisher Scientific, USA). All cell lines were cultured in a humidified $37{ }^{\circ} \mathrm{C}$ incubator (Thermo Fisher Scientific, USA) with $5 \% \mathrm{CO}_{2}$. All cells were counted using Countes II Cell Counter (Thermo Fisher Scientific, USA) before further analysis.

\section{WST-1 analysis}

Equal number $\left(2 \times 10^{4}\right.$ cells/well $)$ of these cells were cultured in 96-well culture plates, then treated alone with different curcumin concentrations $(5-100 \mu \mathrm{M})$ and LPS $(2 \mu \mathrm{M})$ and the combination of curcumin $(5$, 10 and $25 \mu \mathrm{M})$ plus LPS $(2 \mu \mathrm{M})$ for 24 and $48 \mathrm{~h}$. LPS was used to stimulate TLR4 signaling pathway. Following incubation, the cells were then incubated by $10 \mu \mathrm{L}$ of WST-1 reagent (Biovision, San Francisco, CA, USA) at $37^{\circ} \mathrm{C}$ for 30 minutes in the dark conditions. After incubation, the cells were examined at $450 \mathrm{~nm}$ with 96 -well plate reader (Allsheng, China). Each experiment was performed three replicates.

\section{Real-Time PCR analysis}

Real-time polymerase chain reaction (RT-PCR) analysis was performed to analyze the mRNA levels of TLR4 in breast cancer cells treated with curcumin alone $(5,10$ and $25 \mu \mathrm{M})$, LPS alone $(2 \mu \mathrm{M})$ and the combination of curcumin plus LPS. Total RNA was isolated by using E.Z.N.A. ${ }^{\circledR}$ Total RNA Kit (Omega Bio-Tek, Norcross, GA). The purity and concentration of isolated RNAs were determined by Qubit 4 Fluorometer (Thermo Fisher Scientific, Waltham, MA, USA). cDNA was then synthesized by using High Capacity cDNA Reverse Transcription Kit (Thermo Fisher Scientific, Waltham, MA, USA). RT-PCR was performed by TaqMan $^{\text {TM }}$ Gene Expression Assay for determination of mRNA levels of TLR4 in The StepOnePlus ${ }^{\mathrm{TM}}$ Real-Time PCR (Applied Biosystems, Foster City, CA). $\beta$-actin was utilized as the endogenous reference gene. Each experiment was performed in three replicates.

\section{Immunofluorescence analysis}

Equal number $\left(5 \times 10^{5}\right.$ cells/well $)$ of breast cancer cells were cultured on slides and after 24 hours, the cells incubated with LPS $(2 \mu \mathrm{M})$, curcumin $(5,10$ and $25 \mu \mathrm{M})$ and the combination of curcumin plus LPS for 48 hours. Then, the cancer cells were fixed with $4 \%$ cold-paraformaldehyde for 15 minute and were incubated in $5 \%$ goat serum and $1 \%$ Triton X100 in $1 \times$ PBS for $1 \mathrm{~h}$ at room temperature. Then, the cells were treated with primary antibody of TLR4 (1:2000, Santa Cruz Biotechnology, CA, USA) and IFN regulatory factor 3 (IRF3) (1:2000, Santa Cruz Biotechnology, CA, USA) for 4 hours and incubated with secondary antibody (1:1000, Bio-Rad, Hercules, California, USA) for $1 \mathrm{~h}$ at room temperature. Afterwards, the nucleus of cells was 
stained with DAPI. Fluorescent images were photographed and examined with an EVOS FL Cell Imaging System (Thermo Fisher Scientific, USA).

\section{ELISA analysis}

Conditioned medium was collected from breast cancer cells incubated alone with different concentrations of curcumin $(5,10$ and $25 \mu \mathrm{M})$ and LPS $(2 \mu \mathrm{M})$ and the combination of curcumin plus LPS for 48 hours. Concentrations of interferon- $\alpha$ $($ IFN- $\alpha$ ) and interferon- $\beta$ (IFN- $\beta$ ) were analyzed by ELISA kits (Elabscience, USA). Each experiment was conducted in three replicates. Obtained data were shown as mean pg of cytokine \pm S.D. normalized per 100 cells.

\section{Acridine orange (AO) and ethidium bromide (EtBr) staining}

Equal number $\left(5 \times 10^{5}\right.$ cells/well $)$ of cells were cultured in 6-well culture plates and treated alone with LPS $(2 \mu \mathrm{M})$, curcumin $(5,10$ and $25 \mu \mathrm{M})$ and the combination of curcumin plus LPS. Then, all cells were fixed with $4 \%$ cold-paraformaldehyde for 15 minute and the cells were stained by adding 500 $\mu \mathrm{L}$ of $\mathrm{AO} / \mathrm{EtBr}$ for 30 minute in the dark. The cells were examined with EVOS FL Cell Imaging System (Thermo Fisher Scientific, USA).

\section{STATISTICAL ANALYSIS}

All data was statistically evaluated by SPSS 22.0 (SPSS Inc., Chicago, IL, USA). Data were expressed as a mean $\pm \mathrm{SD}$ of the three experiments. The Analysis of Variance (ANOVA) test by Post-Tukey test was conducted for multiple comparisons. $p<0.05$ was considered to be statistically significant. Furthermore,https://dataanalysis.qiagen.com/pcr/arr ayanalysis.php software was used for gene expression analysis.

\section{RESULTS}

\section{Assessment of cell viability}

In order to evaluate curcumin's anti-proliferative effects on breast cancer cells, WST-1 assay was performed (Figure 1). Both breast cancer cells proliferation was significantly inhibited by curcumin $(\mathrm{p}<0.01)$. However, the inhibitory effects of curcumin on MDA-MB-231 cells were greater than MCF-7 cells. The IC50 concentration of curcumin $25.60 \pm 2.83 \mu \mathrm{M}$ and $8.05 \pm 0.70 \mu \mathrm{M}$ in MCF-7 and MDA-MB-231 cells, respectively for $48 \mathrm{~h}$ (Figure
1A). The maximum inhibitions were identified at doses $\geq 25 \mu \mathrm{mol} / 1$ for $48 \mathrm{~h}$ with similar viability percentages. Thus, 5, 10 and $25 \mu \mathrm{M}$ curcumin were selected as suitable doses for further experiments to compare curcumin efficacy in MCF-7 and MDAMB-231 cells. Then, we investigated the antiinflammatory effects of curcumin on LPS-stimulated TLR4 activation in these cells (Figure 1B). We determined that curcumin remarkably inhibited the viability of breast cancer cells by blocking LPS activity $(\mathrm{p}<0.01)$. Thus, curcumin exhibited potential anti-inflammatory activity in breast cancer cell lines.

The TLR4 expression levels in breast cancer cells To investigate the effects of curcumin and LPS alone and the combination of curcumin plus LPS on the mRNA expression level of TLR4 in breast cancer cells, RT-PCR analysis was performed (Figure 2). In principle, MDA-MB-231 cells (13.4- fold) expressed a higher level of TLR4 compared with MCF-7 cells (nearly 10.1- fold) due to aggressive phenotype after LPS stimulation. On the other hand, $25 \mu \mathrm{M}$ curcumin decreased the expression of TLR4 by 1.20 - and $0.54-$ fold in MCF-7 and MDA-MB-231 cells, respectively $(\mathrm{p}<0.01)$. Furthermore, LPS stimulation and $25 \mu \mathrm{M}$ curcumin treatment resulted in a significant 4.68and 1.43- fold increase in TLR4 expression in these cells, respectively $(p<0.01)$. Therefore, our results demonstrated that curcumin treatment suppressed LPS-stimulated TLR4 activation in breast cancer cells.

\section{The subcellular localization of TLR4 and IRF3 in breast cancer cells}

To explore whether curcumin suppresses the activation of IRF3, the subcellular localizations of TLR4 and IRF3 were observed by immunofluorescence staining (Figure 3). We observed the cytoplasmic TLR4 and the nuclear IRF3 proteins following exposure to LPS in breast cancer cells. Furthermore, curcumin decreased the activation of TLR4 and IRF3 because we observed inactive IRF3, which localized in the cytoplasm. However, the cytoplasmic localization of TLR4 and the nuclear localization of IRF3 were detected after treatment with the combination of curcumin with LPS. These results were consistent with gene expression analysis. Our findings suggested that curcumin reduced the endosomal localization of TLR4 and inhibited the nuclear translocation of IRF3 and thus, curcumin could suppress TLR4/TRIF/IRF3 signaling pathway. 


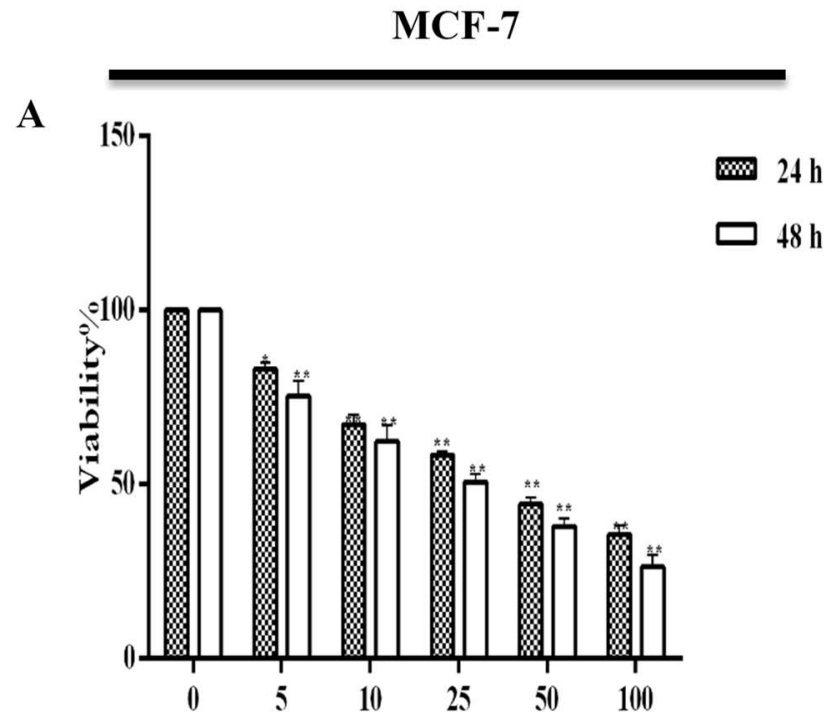

Concentration of Curcumin $(\mu \mathrm{M})$

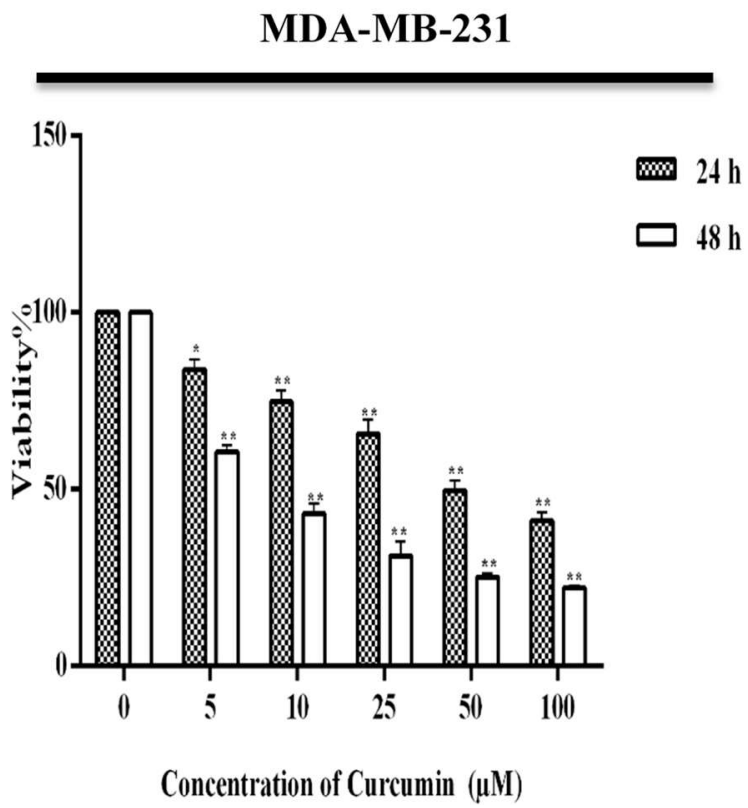

B
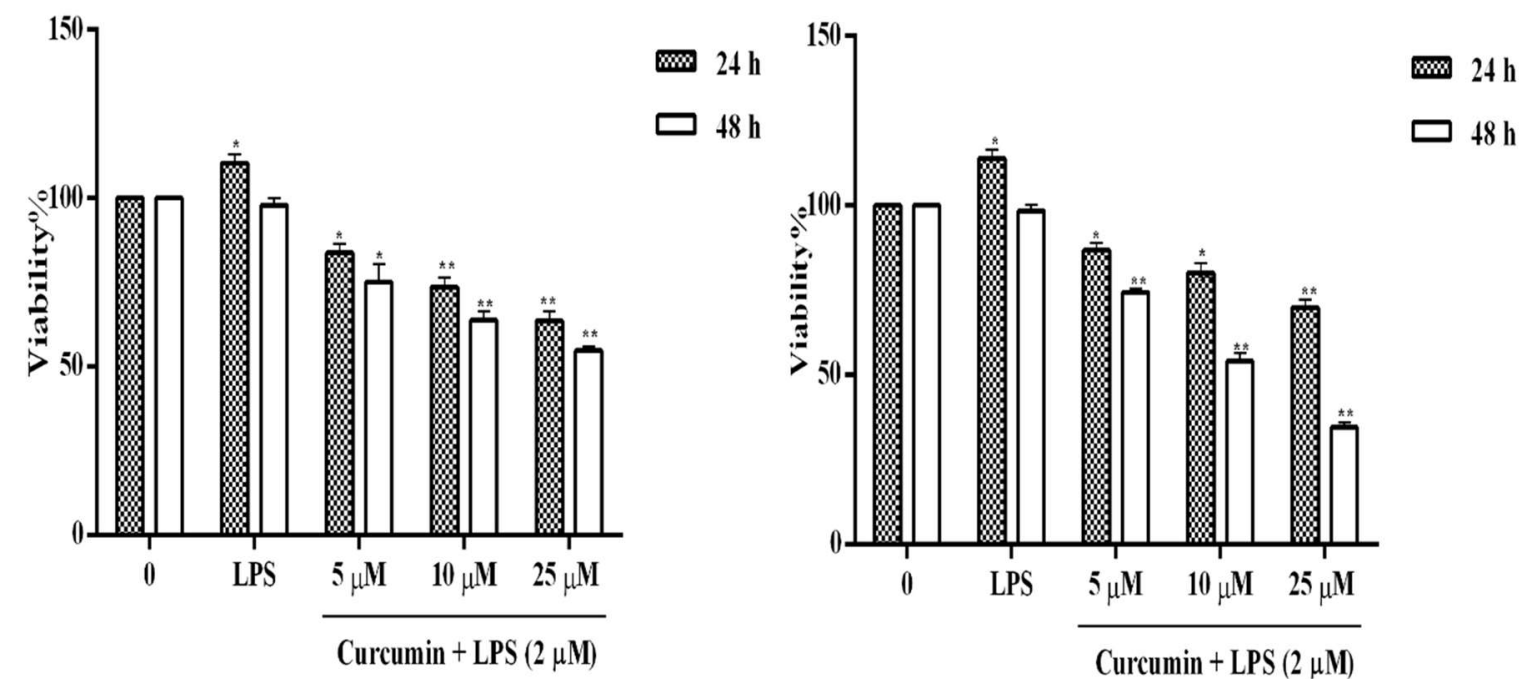

Figure 1. (A) Cytotoxicity of curcumin $(5-100 \mu \mathrm{M})$ in MCF7 and MDA-MB-231 cells. (B) Curcumin inhibited LPS (2 $\mu \mathrm{M})$ stimulated inflammation in both breast cancer cells $\left(\mathrm{p}<0.05^{*}, \mathrm{p}<0.01^{* *}\right)$.

The type I IFN level in breast cancer cells

To further confirm the suppression of IRF3 activity by curcumin, the changes in the level of type I IFN were detected in both breast cancer cells (Figure 4). Treatment of breast cancer cells with LPS alone significantly stimulated the release of IFN- $\alpha$ and IFN- $\beta$ levels $(\mathrm{p}<0.01)$. However, the levels of IFN$\alpha$ and IFN- $\beta$ considerably decreased following treatment with curcumin or the combination of curcumin with LPS $(p<0.01)$. Furthermore, curcumin reduced IFN- $\alpha$ and IFN- $\beta$ levels to a greater extent than curcumin plus LPS combination $(\mathrm{p}<0.01)$. As a result, curcumin and curcumin plus LPS stimulation resulted in a decrease in the level of IFN- $\alpha$ and IFN$\beta$, and thus curcumin suppressed TLR4/TRIF/IRF3 signaling pathway.

\section{Observation of morphological changes in breast} cancer cells

In order to observe morphological changes in breast cancer cell, we used $\mathrm{AO} / \mathrm{EtBr}$ staining (Figure 5). The more rounded cells, plasma membrane blebbing, 
cellular shrinkage, nuclear condensation and fragmentation were observed in both breast cancer cells following incubation with curcumin alone and the combination of curcumin plus LPS. At a concentration of $25 \mu \mathrm{M}$ curcumin, multiple segregated apoptotic bodies were especially noticed

A

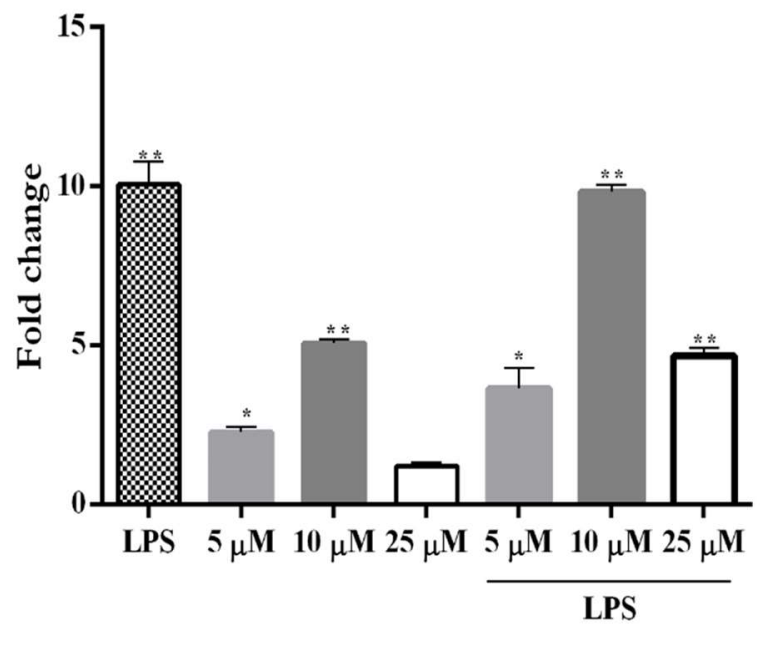

Curcumin in MDA-MB-231 cells. However, LPS stimulation did not alter overall morphology of MCF-7 and MDA-MB-231 cells. Thus, our findings indicated that curcumin suppressed LPS activity in breast cancer cells by inducing apoptotic cell death.

B

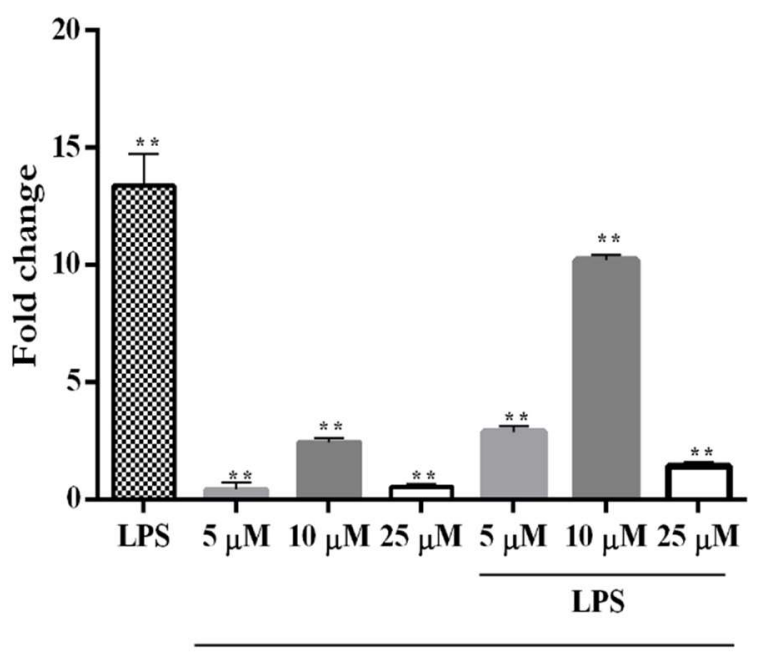

Curcumin

Figure 2. The expression level of TLR4 in (A) MCF-7 and (B) MDA-MB-231 cells after treatment with curcumin and LPS alone and curcumin plus LPS.

\section{DISCUSSION}

Curcumin interacts with multiple molecular targets through a wide range of biological properties $(27-$ 29). In the current study, the anti-inflammatory effects of curcumin on MyD88 independent-TRIF signaling pathway were investigated in breast cancer cell lines, for the first time. Our findings demonstrated that curcumin could potentially suppress LPS-stimulated TLR4/TRIF/IRF3 signaling pathway through the downregulation of TLR4 and IRF3 activity and the inhibition of type I IFN (IFN- $\alpha / \beta)$ levels in breast cancer cells.

Curcumin treatment significantly inhibits the proliferation of different subtypes (MCF7, MDAMB-231 and BT-474 etc.) of breast cancer cells by inducing apoptosis through multiple signaling pathways (30-34). Additionally, the molecular mechanisms underlying curcumin-mediated apoptotic cell death have been identified in the literature (35-38). In the current study, curcumin showed higher toxicity in MDA-MB-231 cells than
MCF-7 cells. Moreover, we observed typical apoptotic morphological in these cells treating with curcumin. However, only a limited number of studies have been demonstrated for the antiinflammatory effects of curcumin on cancer cells. For this purpose, we evaluated the potential effect of curcumin on TLR4 signaling and especially TLR4/TRIF/IRF3 signaling pathway.

TLR4 is mainly expressed in innate immune cells. TLR4 dimerization is crucial for the activation of both the MyD88-dependent and independent TRIF signaling pathways and thus, TLR4 plays an important role in innate immune response. The TLR4/MyD88 independent signaling pathway is mediated by the activation of TRIF, IRF3 and the expression of type I IFNs (IFN- $\alpha / \beta)$ (39-43). Previous studies have shown that TLR4 and MyD88 are over-expressed in breast cancer $(11,12,44,45)$. Some natural compounds (luteolin, epigallocatechin3-gallate, catechin, 6-shogaol) exhibit antiinflammatory effects and mediate

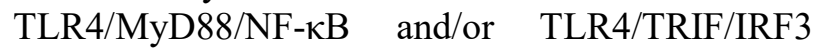


signaling pathways (46-48). Furthermore, several studies have evaluted the anti-inflammatory effects of curcumin on cancer cells (49-51). For instance, Huang et al (2013) state that curcumin significantly inhibits LPS-induced epithelial mesenchymal transition (EMT) in breast cancer cells (MCF-7 and MDA-MB-231 cells) through the downregulation of NF- $\kappa B-S n a i l$ activity (49).

Furthermore, curcumin binds non-covalently to myeloid differentiation protein 2 (MD-2), which is responsible for LPS recognition and thus, inhibits TLR4 mediated signaling pathways in HEK293 cells $(50,51)$. Some recent studies have demonstrated that curcumin reduces TLR4 expression induced by LPS through the TLR4/MyD88/NF- $\mathrm{KB}$ signaling pathway in traumatic brain injury and also atherosclerosis $(52,53)$. In the present study, our findings suggest that curcumin could potentially inhibit the activation of LPS-stimulated TLR4/TRIF/IRF3 pathway in breast cancer cells.

A

(a)

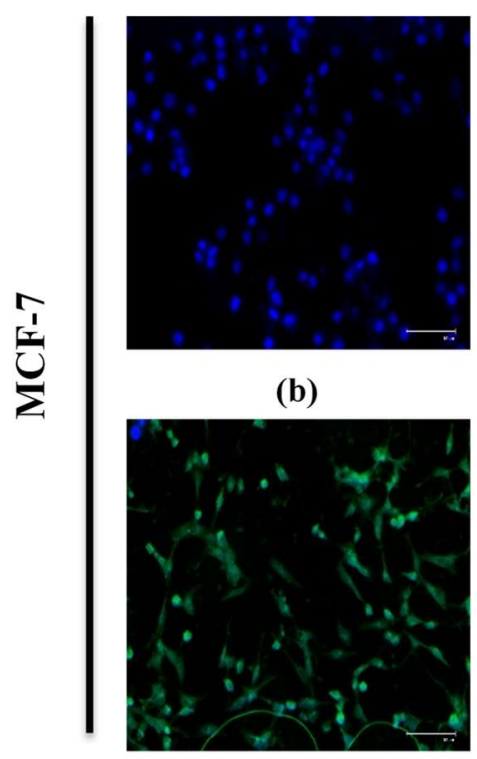

(a)

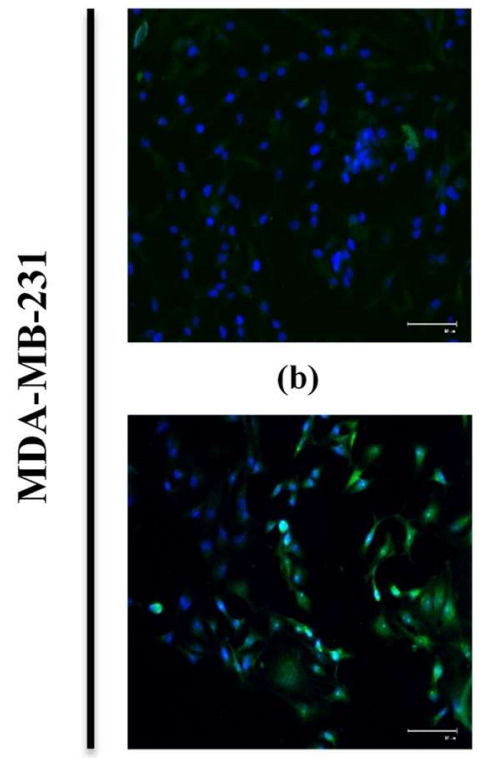

(c)

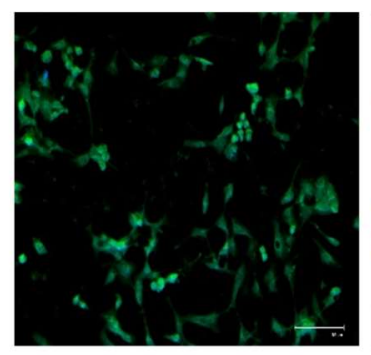

(d)

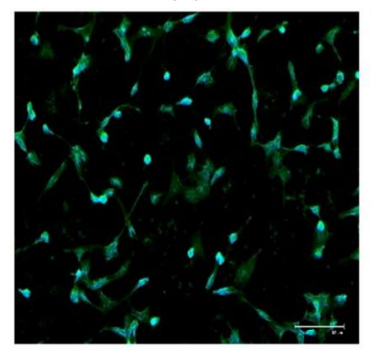

(c)

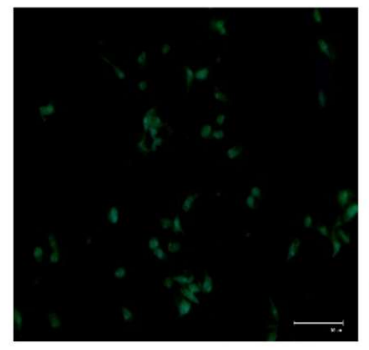

(d)

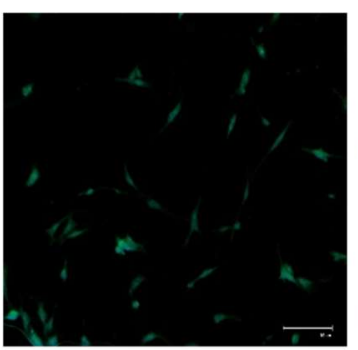

(e)

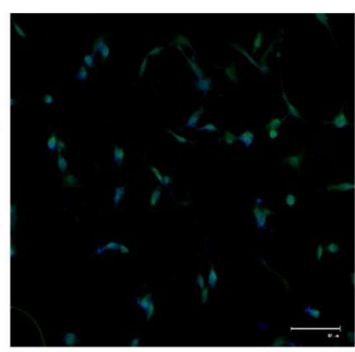

(f)

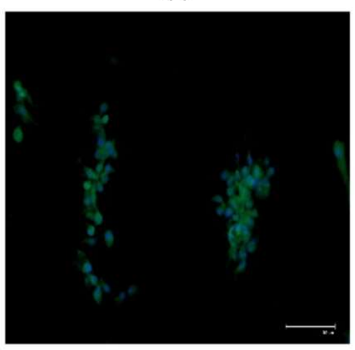

(e)

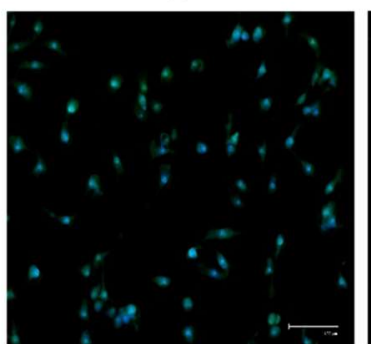

(f)

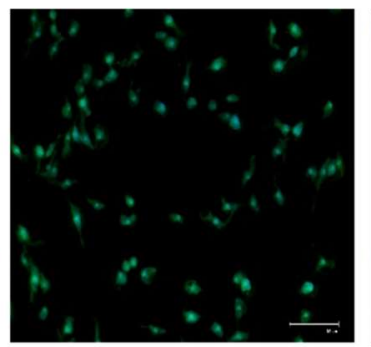

(g)

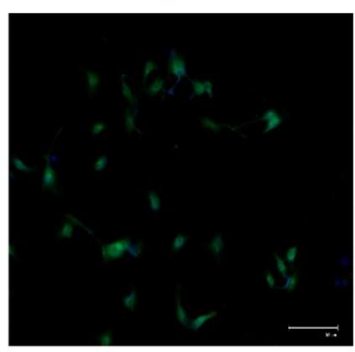

(h)

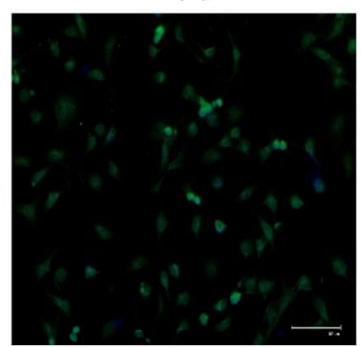

(g)

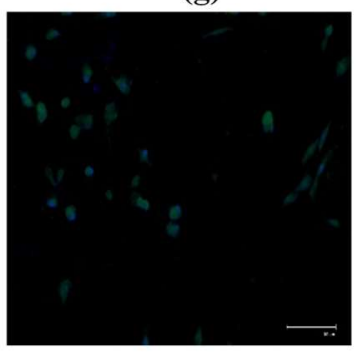

(h)

Figure 3 Continued... 
B

(a)

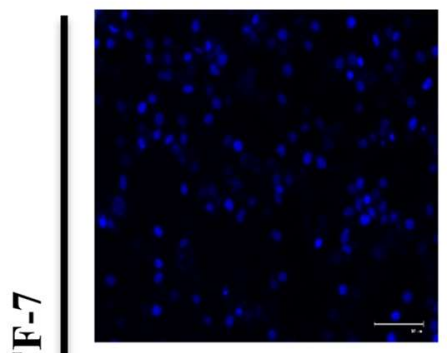

(b)

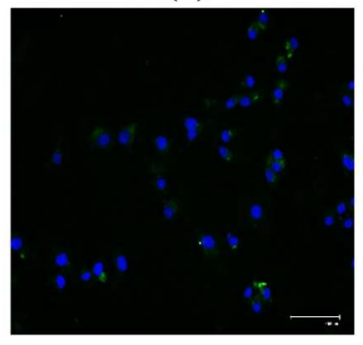

(a)

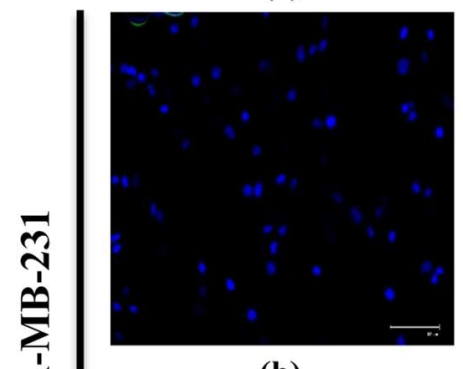

(b)

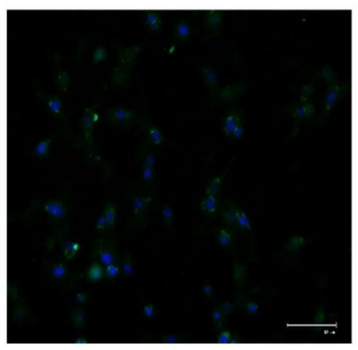

(c)

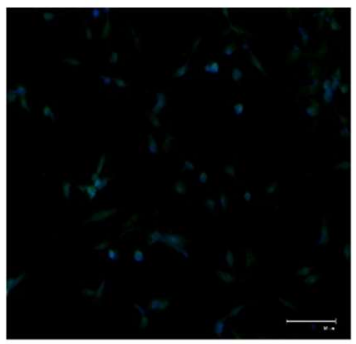

(d)

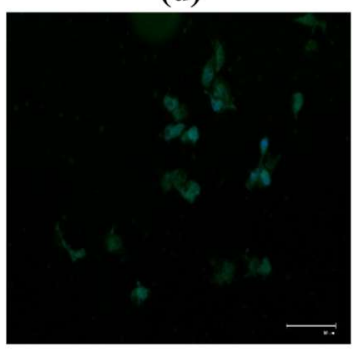

(c)

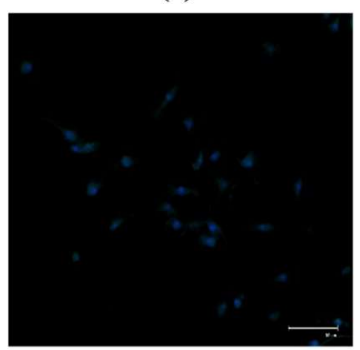

(d)

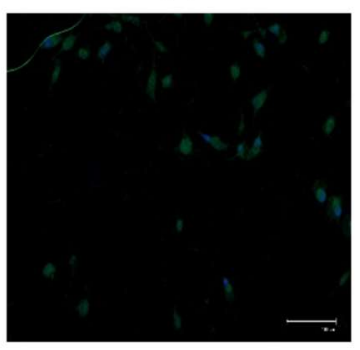

(e)

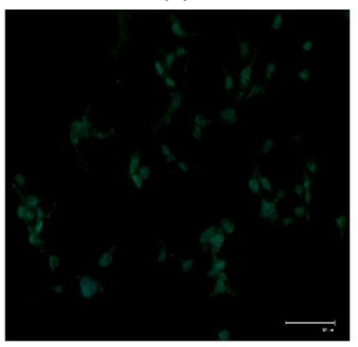

(f)

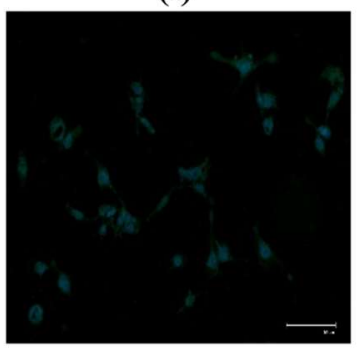

(e)

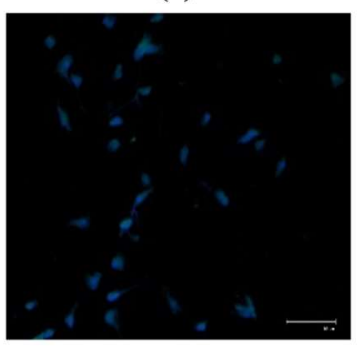

(f)

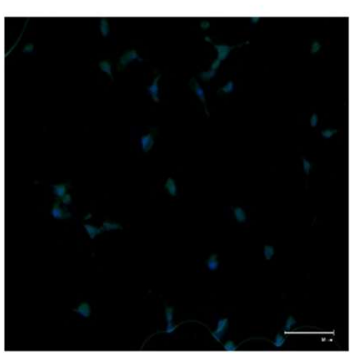

(g)

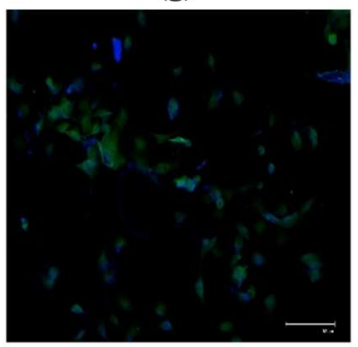

(h)

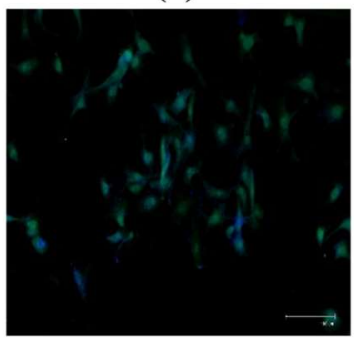

(g)

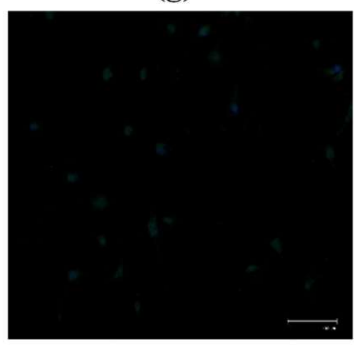

(h)

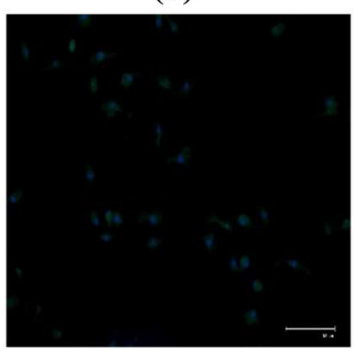

Figure 3. The subcellular localization of (A) TLR4 and (B) IRF3 in MCF-7 and MDA-MB-231 cells was observed by immunofluorescence staining following incubation with (a) Control, (b) LPS, (c) $5 \mu \mathrm{M}$ curcumin, (d) $5 \mu \mathrm{M}$ curcumin + LPS, (e) $10 \mu \mathrm{M}$ curcumin, (f) $10 \mu \mathrm{M}$ curcumin + LPS, (g) $25 \mu \mathrm{M}$ curcumin and (h) $25 \mu \mathrm{M}$ curcumin + LPS, respectively. (Green: TLR4 or IRF3 expression, blue: nuclei).

Stimulation of TLR4 by LPS increased the viability of MCF-7 and MDA-MB-231 cells as well as the induction of IRF 3 translocation and IFN- $\alpha$ and IFN$\beta$ levels. However, curcumin alone and the combination of curcumin with LPS remarkably reduced the activation of TLR4/TRIF/IRF3 pathway through the downregulation of TLR4 and IRF3 in breast cancer cells. Additionally, our findings demonstrated that IFN- $\alpha$ and IFN- $\beta$ levels reduced after exposure to curcumin in LPS stimulated breast cancer cells. Nevertheless, MDA-MB-231 cells were more susceptible to curcumin anti-inflammatory activity than MCF-7 cells. 
A

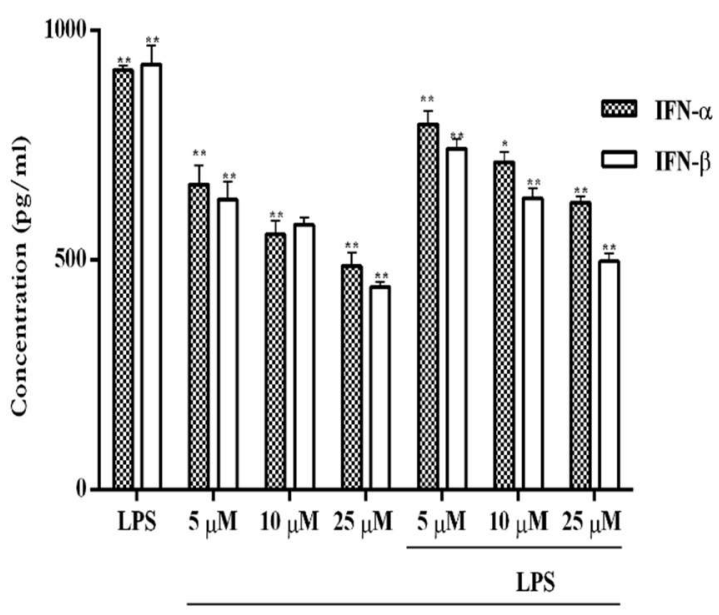

Curcumin
B

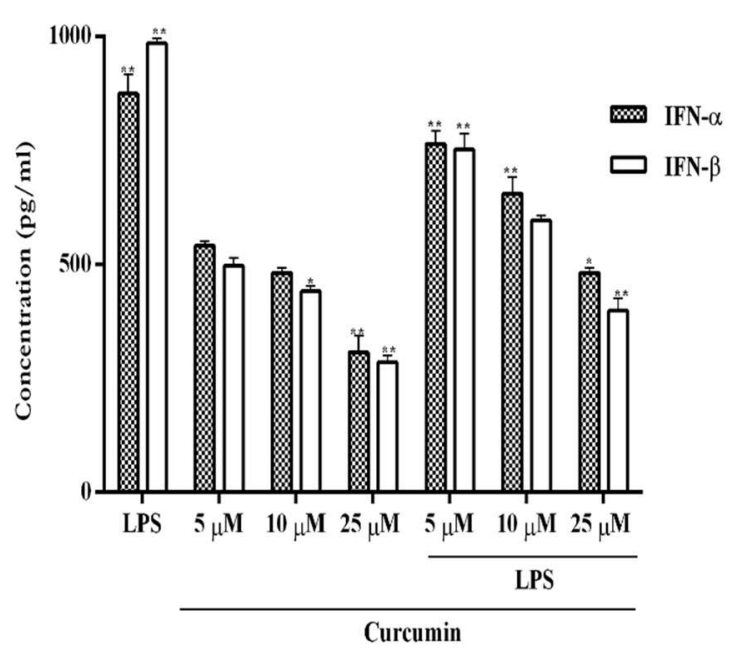

Figure 4. The secreted IFN- $\alpha$ and IFN- $\beta$ levels were detected in (A) MCF-7 and (B) MDA-MB-231 cells in response to curcumin and LPS alone and curcumin and LPS combination ( $\left.<<0.05^{*}, \mathrm{p}<0.01^{* *}\right)$.

(a)

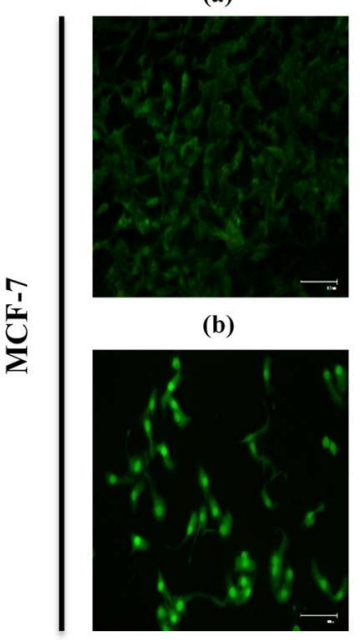

(a)

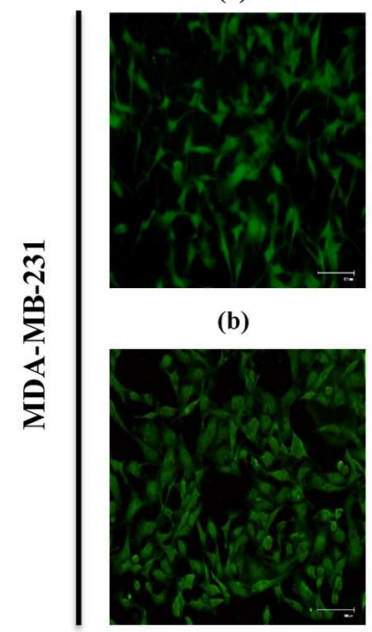

(c)

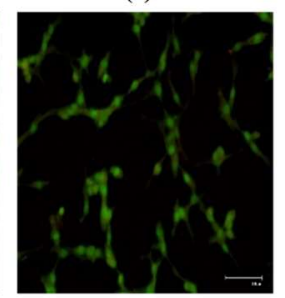

(d)

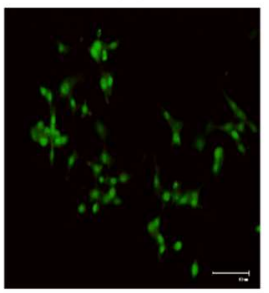

(c)

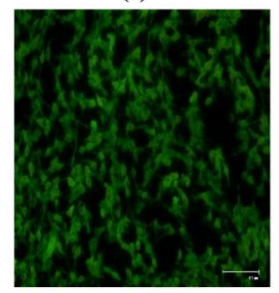

(d)

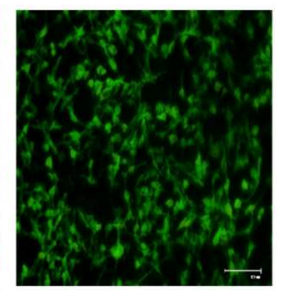

(e)

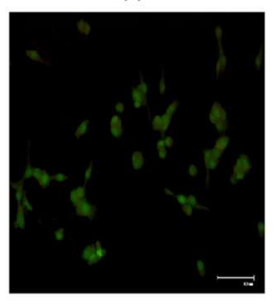

(f)

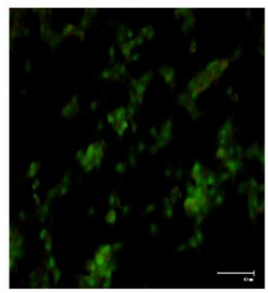

(e)

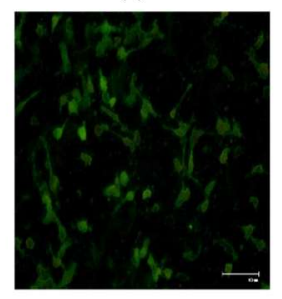

(f)

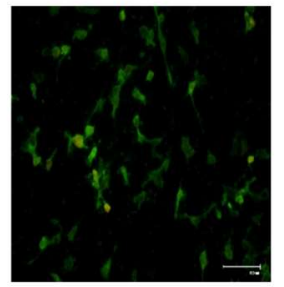

(g)

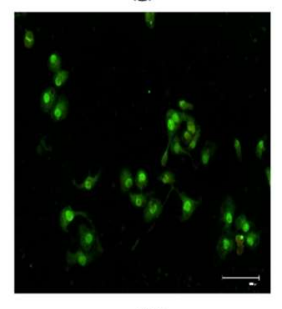

(h)

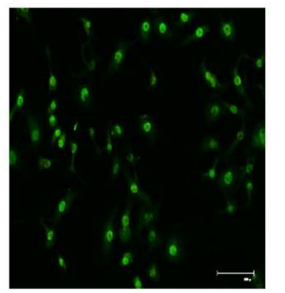

(g)

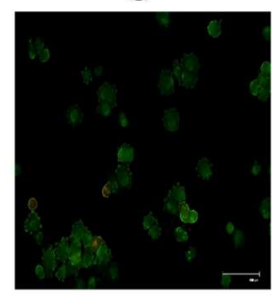

(h)

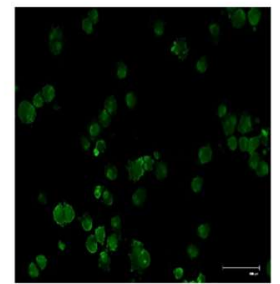

Figure 5. Curcumin and LPS alone and curcumin and LPS-induced apoptotic cell death in the MCF-7 and MDA-MB-231 cells observed by AO/EtBr staining. [(a) Control, (b) LPS, (c) $5 \mu \mathrm{M}$ curcumin, (d) $5 \mu \mathrm{M}$ curcumin + LPS, (e) $10 \mu \mathrm{M}$ curcumin, (f) $10 \mu \mathrm{M}$ curcumin + LPS, (g) $25 \mu \mathrm{M}$ curcumin and (h) $25 \mu \mathrm{M}$ curcumin + LPS, respectively]. 
However, the potential effects of curcumin on the TLR4/MyD88/NF- $\mathrm{BB}$ signaling pathway as well as the activation of different TLRs and downstream signaling pathways should be further elucidated.

In conclusion, we evaluated that curcumin exerted TLR4 antagonist activity in two different subtypes of breast cancer cells through its antiinflammatory effects and could mediate TLR4/TRIF/IRF3 signaling pathway and IFN responses by suppressing of LPS stimulated inflammation. However, further molecular studies are needed to explore the relationship between curcumin anti-inflammatory action and LPS induced TLR4/TRIF/IRF3 and TLR4/MyD88/NF- $\kappa B$ signaling pathways in breast cancer, in detail. Additionally, the link between curcumin and other signaling pathways via TLRs activation requires further investigation, in vitro.

\section{CONFLICT OF INTEREST}

The authors declare that they have no conflict of interest.

\section{ACKNOWLEDGEMENT}

This study was supported by a grant from the Scientific Research Projects Foundation (BAP) of the Sakarya University of Turkey [Project No: 20183-12-295].

\section{REFERENCES}

1. Takeda K, Akira S. Toll-like receptors in innate immunity. Int Immunol, 2005; 17:1-14. doi: 10.1093/intimm/dxh186.

2. Takeda K, Kaisho T, Akira S. Toll-like receptors. Annu Rev Immunol, 2003; 21:335-76. doi: 10.1146/annurev.immunol.21.120601.141126.

3. Janeway CA. Jr. Approaching the a symptote? Evolution and revolution in immunology. Cold Spring Harb Symp Quant Biol, 1989; 54:1-13. doi:10.1101/SQB.1989.054.01.003

4. Zhao S, Zhang Y, Zhang Q, Wang F, Zhang D. Tolllike receptors and prostate cancer. Front Immunol, 2014; 23:5-352. doi: 10.3389/fimmu.2014.00352.

5. Curtin JF, Liu N, Candolfi M, Xiong W, Assi H, Yagiz K, Edwards MR, Michelsen KS, Kroeger KM, Liu C, Muhammad AK, Clark MC, Arditi M, CominAnduix B, Ribas A, Lowenstein PR, Castro MG. HMGB1 mediates endogenous TLR2 activation and brain tumor regression. PLoS Med, 2009; 13:6(1):e10. doi:10.1371/journal.pmed.1000010.
6. Fukata M, Chen A, Vamadevan AS, Cohen J, Breglio $\mathrm{K}$, Krishnareddy S, Hsu D, Xu R, Harpaz N, Dannenberg AJ, Subbaramaiah K, Cooper HS, Itzkowitz SH, Abreu MT. Toll-like receptor-4 promotes the development of colitis-associated colorectal tumors. Gastroenterology, 2007; 133:1869-1881. doi: 10.1053/j.gastro.2007.09.008.

7. Goto Y, Arigami T, Kitago M, Nguyen SL, Narita N, Ferrone S, Morton DL, Irie RF, Hoon DS. Activation of Toll-like receptors 2, 3, and 4 on human melanoma cells induces inflammatory factors. Mol Cancer Ther, 2008; 7(11):3642-53. doi: 10.1158/1535-7163.

8. He W, Liu Q, Wang L, Chen W, Li N, Cao X. TLR4 signaling promotes immune escape of human lung cancer cells by inducing immunosuppressive cytokines and apoptosis resistance. Mol Immunol, 2007; 44:2850-2859. DOI: 10.1016/j.molimm.2007.01.022.

9. Ilvesaro JM, Merrell MA, Swain TM, Davidson J, Zayzafoon M, Harris KW, Selander KS. Toll like receptor-9 agonists stimulate prostate cancer invasion in vitro. Prostate, 2007; 67:774-781. doi: 10.1002/pros.20562.

10. Poltorak A, He X, Smirnova I, Liu MY, Van Huffel C, Du X, Birdwell D, Alejos E, Silva M, Galanos C, Freudenberg M, Ricciardi-Castagnoli P, Layton B, Beutler B. Defective LPS signaling in $\mathrm{C} 3 \mathrm{H} / \mathrm{HeJ}$ and $\mathrm{C} 57 \mathrm{BL} / 10 \mathrm{ScCr}$ mice: mutations in Tlr4 gene. Science, 1998; 282:2085-8. DOI: 10.1126/science.282.5396.2085.

11. Yang H, Zhou H, Feng P, Zhou X, Wen H, Xie X, Shen H, Zhu X. Reduced expression of Toll-like receptor 4 inhibits human breast cancer cells proliferation and inflammatory cytokines secretion. J Exp Clin Cancer Res, 2010; 10:29:92. doi: 10.1186/1756-9966-29-92.

12. Yang H, Wang B, Wang T, Xu L, He C, Wen H, Yan J, Su H, Zhu X. Toll-like receptor 4 prompts human breast cancer cells invasiveness via lipopolysaccharide stimulation and is overexpressed in patients with lymph node metastasis. PLoS One, 2014; 9:9(10):e109980. doi: 10.1371/journal.

13. Kuzmich N, Sivak K, Chubarev V, Porozov Y, Savateeva-Lyubimova T, Peri F. TLR4 signaling pathway modulators as potential therapeutics in inflammation and sepsis. Vaccines, 2017; 5(4), 34. doi: 10.3390/vaccines5040034.

14. Molteni M, Bosi A, Rossetti C. Natural Products with Toll-Like Receptor 4 Antagonist Activity. Int J Inflam, 2018; $1: 2859135$. doi:10.1155/2018/2859135.

15. Lu YC, Yeh WC, Ohashi PS. LPS/TLR4 signal transduction pathway. Cytokine, 2008; 42(2), 145151. doi: 10.1016/j.cyto.2008.01.006.

16. Kawasaki $\mathrm{T}$, Kawai $\mathrm{T}$. Toll-like receptor signaling pathways. Frontiers in immunology, 2014; 5, 461. doi: 10.3389/fimmu.2014.00461. 
17. Joe B, Vijaykumar M, Lokesh BR. Biological properties of curcumin-cellular and molecular mechanisms of action. Crit Rev Food Sci Nutr, 2004; 44:97-111.

18. Goel A. Aggarwal BB. Curcumin, the golden spice from Indian saffron, is a chemosensitizer and radiosensitizer for tumors and chemoprotector and radioprotector for normal organs. Nutr Cancer, 2010; 62:919-930. doi: 10.1080/01635581.2010.509835.

19. Basnet P, Skalko-Basnet N. Curcumin: an antiinflammatory molecule from a curry spice on the path to cancer treatment. Molecules, 2011; 16:4567-4598. doi: 10.3390/molecules 16064567.

20. Calaf GM, Ponce-Cusi R, Carrión F. Curcumin and paclitaxel induce cell death in breast cancer cell lines. Oncol Rep, 2018; 40(4):2381-23885. doi: 10.3892/or.2018.6603.

21. Fahey AJ, Adrian Robins R. Constantinescu CS. Curcumin modulation of IFN- $\beta$ and IL-12 signalling and cytokine induction in human T cells. J Cell Mol Med, 2007; 11(5):1129-1137. DOI: 10.1111/j.15824934.2007.00089.x.

22. Boozari M, Butler AE, Sahebkar A. Impact of curcumin on toll-like receptors. J Cell Physiol, 2019;1-12. doi: 10.1002/jcp.28103.

23. Kim J, Durai P, Jeon D, Jung ID, Lee SJ, Park YM, Kim Y. Phloretin as a Potent Natural TLR2/1 Inhibitor Suppresses TLR2-Induced Inflammation. Nutrients, 2018; 5:10(7), pii: E868. DOI: 10.3390/nu10070868.

24. Gao H, Liu X, Sun W, Kang N, Liu Y, Yang S, Xu QM, Wang C, Chen X. Total tanshinones exhibits anti-inflammatory effects through blocking TLR4 dimerization via the MyD88 pathway. Cell Death Dis, 2017; 17:8(8):e3004. doi:10.1038/cddis.2017.389.

25. Chung HJ, Koh W, Kim WK, Shin JS, Lee J, Lee SK, Ha IH. The Anti-Inflammatory Effects of Shinbaro3 Is Mediated by Downregulation of the TLR4 Signalling Pathway in LPS-Stimulated RAW 264.7 Macrophages. Mediators Inflamm, 2018; 5:2018:4514329. doi: 10.1155/2018/4514329.

26. Arreola R, Quintero-Fabián S, López-Roa RI, FloresGutiérrez EO, Reyes-Grajeda JP, Carrera-Quintanar L, Ortuño-Sahagún D. Immunomodulation and antiinflammatory effects of garlic compounds. J Immunol Res, 2015;2015:401630. doi:10.1155/2015/401630.

27. Patel SS, Acharya A, Ray RS, Agrawal R, Raghuwanshi R, Jain P. Cellular and molecular mechanisms of curcumin in prevention and treatment of disease. Crit Rev Food Sci Nutr, 2019; 11:1-53. doi: 10.1080/10408398.2018.1552244.

28. Zhou H, Beevers CS, Huang S. The targets of curcumin. Curr Drug Targets, 2011; 12(3):332-47. doi : $10.2174 / 138945011794815356$

29. Lin JK. Molecular targets of curcumin. Adv Exp Med Biol, 2007; 595:227-43. doi: 10.1007/978-0-38746401-5_10.
30. Banik U, Parasuraman S, Adhikary AK, Othman NH. Curcumin: the spicy modulator of breast carcinogenesis. J Exp Clin Cancer Res, 2017; 36(1):98. doi: 10.1186/s13046-017-0566-5.

31. Sun XD, Liu XE, Huang DS. Curcumin induces apoptosis of triple-negative breast cancer cells by inhibition of EGFR expression. Mol Med Rep, 2012; 6(6):1267-70. doi: 10.3892/mmr.2012.1103.

32. Choudhuri T, Pal S, Agwarwal ML, Das T, Sa G. Curcumin induces apoptosis in human breast cancer cells through p53-dependent Bax induction. FEBS Lett, 2002; 512(1-3):334-40. https://doi.org/10.1016/S0014-5793(02)02292-5.

33. Liu D, Chen Z. The effect of curcumin on breast cancer cells. J Breast Cancer, 2013; 16 (2):133-137. doi:10.4048/jbc.2013.16.2.133

34. Prasad CP, Rath G, Mathur S, Bhatnagar D, Ralhan R. Potent growth suppressive activity of curcumin in human breast cancer cells: Modulation of Wnt/betacatenin signaling. Chem Biol Interact, 2009; 7:181(2):263-71. doi:10.1016/j.cbi.2009.06.012.

35. Shehzad A, Lee YS. Molecular mechanisms of curcumin action: signal transduction. Biofactors, 2013; 39(1):27-36. doi: 10.1002/biof.1065.

36. Sa G, Das T. Anti-cancer effects of curcumin: cycle of life and death. Cell Div, 2008; 3:14. doi: 10.1186/1747-1028-3-14.

37. Woo JH, Kim YH, Choi YJ, Kim DG, Lee KS, Bae JH, Min DS, Chang JS, Jeong YJ, Lee YH, Park JW, Kwon TK. Molecular mechanisms of curcumininduced cytotoxicity: induction of apoptosis through generation of reactive oxygen species, downregulation of $\mathrm{Bcl}-\mathrm{XL}$ and IAP, the release of cytochrome $\mathrm{c}$ and inhibition of Akt. Carcinogenesis, 2003; 24(7):1199-208. DOI: 10.1093/carcin/bgg082.

38. Reuter S, Eifes S, Dicato M, Aggarwal BB, Diederich M. Modulation of anti-apoptotic and survival pathways by curcumin as a strategy to induce apoptosis in cancer cells. Biochem Pharmacol, 2008; 76(11):1340-51. doi:10.1016/j.bcp.2008.07.031.

39. Kumar H, Kawai T, Akira S. Pathogen recognition by the innate immune system. Int Rev Immunol, 2011; 30(1):16-34. doi: 10.3109/08830185.2010.529976.

40. O'Neill LA, Bowie AG. The family of five: TIRdomain-containing adaptors in Toll-like receptor signalling. Nat Rev Immunol, 2007; 7(5):353-64. DOI: $10.1038 /$ nri2079.

41. Honda K, Taniguchi T. IRFs: master regulators of signalling by Toll-like receptors and cytosolic pattern-recognition receptors. Nat Rev Immunol, 2006; 6(9):644-58. DOI: 10.1038/nri1900.

42. O'Neill LA. How Toll-like receptors signal: what we know and what we don't know. Curr Opin Immunol, 2006; 18(1):3-9. DOI: 10.1016/j.coi.2005.11.012.

43. De Nardo D. Toll-like receptors: Activation, signalling and transcriptional modulation. Cytokine, 2015; 74(2):181-9. doi: 10.1016/j.cyto.2015.02.025. 
44. So EY, Ouchi T. The application of Toll like receptors for cancer therapy. Int J Biol Sci, 2010; 6(7):675-681. doi:10.7150/ijbs.6.675.

45. González-Reyes S, Marín L, González L, González LO, del Casar JM, Lamelas ML, González-Quintana JM, Vizoso FJ. Study of TLR3, TLR4 and TLR9 in breast carcinomas and their association with metastasis. BMC Cancer, 2010; 10:665. doi: 10.1186/1471-2407-10-665.

46. Youn HS, Lee JY, Saitoh SI, Miyake K, Kang KW, Choi YJ, Hwang DH. Suppression of MyD88- and TRIF-dependent signaling pathways of Toll-like receptor by (-)-epigallocatechin-3-gallate, a polyphenol component of green tea. Biochem Pharmacol, 2006; 72(7):850-9. DOI: 10.1016/j.bcp.2006.06.021.

47. Lee JK, Kim SY, Kim YS, Lee WH, Hwang DH, Lee JY. Suppression of the TRIF-dependent signaling pathway of Toll-like receptors by luteolin. Biochem Pharmacol., 2009; 77(8):1391-400. doi: 10.1016/j.bcp.2009.01.009.

48. Ahn SI, Lee JK, Youn HS. Inhibition of homodimerization of toll-like receptor 4 by 6shogaol. Mol Cell, 2009; 27(2): 211-215. doi:10.1007/s10059-009-0026-y.

49. Huang T, Chen Z, Fang L. Curcumin inhibits LPSinduced EMT through downregulation of NF- $\mathrm{kB}$ Snail signaling in breast cancer cells. Oncol Rep, 2013; 29(1):117-24. doi: 10.3892/or.2012.2080.

50. Gradisar H, Keber MM, Pristovsek P, Jerala R. MD2 as the target of curcumin in the inhibition of response to LPS. J Leukoc Biol, 2007; 82(4):968-74. doi: 10.1189/jlb.1206727.

51. Wang Z, Chen G, Chen L, Liu X, Fu W, Zhang Y, Li $\mathrm{C}$, Liang G, Cai Y. Insights into the binding mode of curcumin to MD-2: studies from molecular docking, molecular dynamics simulations and experimental assessments. Mol Biosyst. 2015; 11(7):1933-8. doi: $10.1039 / \mathrm{c} 5 \mathrm{mb} 00085 \mathrm{~h}$.

52. Zhang S, Zou J, Li P, Zheng X, Feng D. Curcumin protects against atherosclerosis in apolipoprotein Eknockout mice by inhibiting toll-like receptor 4 expression. Journal of agricultural and food chemistry 2018; 66(2), 449-456. doi: 10.1021/acs.jafc.7b04260.

53. Zhu HT, Bian C, Yuan JC, Chu WH, Xiang X, Chen F, Wang CS, Feng H, Lin JK. Curcumin attenuates acute inflammatory injury by inhibiting the TLR4/MyD88/NF- $\mathrm{KB}$ signaling pathway in experimental traumatic brain injury. Journal of neuroinflammation 2014; 11(1), 59. doi: 10.1186/1742-2094-11-59. 